Bio-grafia: Escritos sobre la Biologia y su Enseñanza Vol. 5 No 9. Monográfico de Evolución. ISSN 2027-1034. Julio a Diciembre del 2012 P. p. 67-79.

\title{
¿ES LA ENDOSIMBIOSIS SERIADA UNA ALTERNATIVA A LA TEORÍA SINTÉTICA DE LA EVOLUCIÓN? IMPLICACIONES EPISTEMOLÓGICAS Y DIDÁCTICAS
}

\section{IS THE SERIAL ENDOSYMBIOSIS AN ALTERNATIVE TO THE SYNTHETIC THEORY OF EVOLUTION? EPISTEMOLOGICAL AND DIDACTIC IMPLICATIONS}

Recibido: 27-09-2012

Aceptado: 06-12-2012

\section{Por: Germán Alberto Chaves Mejía}

\section{Resumen}

A través de una revisión histórico-epistemológica de algunos de los aspectos más relevantes de la teoría sintética de la evolución (TSE) y de la teoría de la endosimbiosis seriada (TES), el presente ensayo pretende mostrar las principales diferencias epistemológicas y conceptuales de ambas teorías, llegando a la conclusión de que muy posiblemente la teoría de la endosimbiosis seriada que explica el origen de la célula eucariota, como también de otros organismos, podría ser una alternativa a la teoría sintética de la evolución, esto en virtud de que la TES difiere radicalmente en dos de los presupuestos conceptuales y epistemológicos fundamentales de la TSE, como son la evolución de una manera gradualista y la selección natural como principal motor evolutivo. En cuanto al primer aspecto, la TES propone que los cambios evolutivos importantes en eventos claves de la evolución biológica, como la aparición de la célula eucariota, se han dado de una manera no gradual y más acorde con un modelo de evolución biológica a saltos. En cuanto al segundo aspecto, es decir la preponderancia de la selección natural en el proceso evolutivo, la TES propone que esta solo juega un papel de ajuste fino de los organismos a su ambiente, sin que la selección natural llegue a ser la causa principal del origen de nuevas especies. En su lugar la TES propone la simbiosis como una posible causa del origen de nuevas especies. Igualmente, este ensayo propone que reconocer estos debates conceptuales y epistemológicos es clave en los procesos de enseñanzaaprendizaje de la biología en general y de la evolución biológica en particular, en pos de superar una enseñanza de la biología que, de una manera sesgada y hegemónica, solo tenga en cuenta los presupuestos conceptuales y epistemológicos del neodarwinismo.

Palabras clave: Teoría sintética de la evolución, endosimbiosis seriada, eucariota, epistemología, conceptualización.

\section{Abstract}

Through a historical-epistemological revision of some of the most relevant aspects of the synthetic theory of evolution (STE) and the serial endosymbiosis theory (SET), this essay aims to show the main epistemological and conceptual differences in both theories, arriving at the conclusion that the serial endosymbiosis theory likely explains the origin of the eukaryotic cell, as well as other organisms, could be an alternative to the synthetic

\footnotetext{
${ }^{1}$ Biólogo, Universidad Nacional, Bogotá. Especialista en la Enseñanza de la Biología, Universidad Pedagógica Nacional, Bogotá. Magíster, Universidad Nacional, Bogotá. Correo electrónico:
} germanchavesmejia@yahoo.com.co 
theory of evolution, because the STE differs greatly in two of the conceptual and epistemological fundamentals of the STE, as they are, evolution in a gradual way and natural selection as the main evolutive force. Regarding the first aspect, the SET proposes that important evolutionary changes in key events of biological evolution, such as the emergence of the eukaryotic cell, have not occurred in a gradual way and coincide better with a model of biological evolution jumps. In relation to the second aspect, it means, the preponderance of natural selection in the evolutionary process, SET proposes that it only plays a role of fine adjustment of organisms to their environment, without natural selection may become the leading cause of the origin of new species. Instead, the SET proposes symbiosis as a possible cause of the origin of new species. Likewise, this paper proposes to recognize that these conceptual and epistemological debates are essential for biology teaching and learning in general, and particularly biological evolution, in search of overcoming a biased and hegemonic biology teaching that only considers the conceptual and epistemological assumptions of neo-Darwinism.

Keywords: Synthetic theory of evolution, serial endosymbiosis, eukaryote, epistemology, conceptualization.

\section{Introducción}

La evolución biológica -la diversificación de todos los seres vivos a partir de un único ancestro común (o unos pocos) - es una teoría que está ampliamente aceptada por la comunidad científica. Lo anterior está soportado por un sinnúmero de datos y evidencia, aportados meticulosa y sistemáticamente por la comunidad científica a lo largo de los últimos dos siglos. Se podría decir que prácticamente ninguna persona perteneciente a la comunidad académica y/o científica cuestiona esta teoría; no obstante, existen cuestionamientos desde otros ámbitos sociales que muchas veces están basados en la ignorancia o en el fundamentalismo dogmático (Sampedro, 2007). Se podría llenar este apartado de citas dadas por otros eruditos en el tema que concordarían con lo expuesto por el científico, divulgador y periodista español Javier Sampedro; por mencionar algunos de los más destacados, se tiene a Crick (1981), Dawkins (1986, 2009), Mayr (1995, 1998, 2006), Eldredge (1995), Ruse (2008) y Gould (2010).

No obstante lo anterior, la dinámica y los mecanismos de la evolución están en candente discusión y el debate sobre ellos está abierto. Se evidencia, además, la ausencia de un marco filosófico epistemológico adecuado para explicar una naturaleza esencialmente dinámica y cambiante. Al respecto, Gould (1994) enfatiza este planteamiento diciendo:

[La teoría de la evolución] es, en el momento actual de su desarrollo, lo suficientemente sólida para ofrecernos satisfacciones y confianza $\mathrm{y}$, no obstante, está fructíferamente tan poco desarrollada como para ofrecernos un arcón de tesoros rebosantes de misterios. (Gould, 1994, pp. 9-10)

Teorías evolutivas como la hipótesis Evo-Devo (evolutionary and development biology), los equilibrios puntuados, evolución modular, endosimbiosis seriada, entre otras, difieren conceptualmente y epistemológicamente de algunos de los planteamientos propuestos por la teoría sintética de la evolución. 
En este orden de ideas, el presente ensayo pretende mostrar cómo la teoría evolutiva de la endosimbiosis seriada, que explica el origen de las células eucariotas, difiere radicalmente en algunos aspectos de lo propuesto por la teoría sintética de la evolución, considerándose que puede llegar a ser una alternativa a esta, según algunos autores, debido a que entre sus presupuestos conceptuales propone que los cambios evolutivos importantes, en eventos tan relevantes en la evolución biológica como la aparición de la célula eucariota, se han dado de una manera no gradual, como lo propone la síntesis moderna. También es clave que la teoría de la endosimbiosis seriada considera que la selección natural (principal base conceptual de la síntesis moderna), solo juega un papel de ajuste fino de los organismos a su ambiente, sin que esta llegue a ser la causa principal del origen de nuevas especies. En su lugar propone que el fenómeno de la simbiosis podría ser la causa del origen de nuevas especies y por tanto de la biodiversidad.

Este ensayo también resalta que la enseñanza en las escuelas de teorías como la endosimbiosis seriada, es prácticamente nula, ya que si bien es cierto que la evolución biológica es parte del programa curricular de biología, esta se enseña muy superficialmente, y de una manera hegemónica, desde el marco conceptual del neodarwinismo y la teoría sintética de la evolución. A este respecto, este escrito evidencia la importancia de la enseñanza de la evolución biológica basada en presupuestos no necesariamente neodarwinistas, en pos de mejorar los procesos de enseñanzaaprendizaje de la biología en general y de la evolución biológica en particular.

\section{La teoría sintética de la evolución}

Por extraño que parezca, el surgimiento del neodarwinismo y su consolidación con la síntesis moderna o teoría sintética de la evolución, ideas que dominaron la biología en la segunda mitad del siglo XX, y que hoy en día aún se consideran muy relevantes por algunos sectores académicos, florecieron en parte como respuesta al ocaso del darwinismo a finales del siglo XIX y principios del XX, periodo que fue llamado por Julian Huxley como "el eclipse del darwinismo" (Bowler, 1985). Debido a que el éxito inicial de El origen de las especies de Darwin se cimentó en la idea de la evolución como tal, no en el reconocimiento por parte de la comunidad científica de la selección natural como principal motor del cambio evolutivo, comenzó la crisis del darwinismo y esta se acrecentó, entre otros factores, por la falta de acuerdo sobre las causas de la evolución, el papel del ambiente en los cambios evolutivos, las fallas del registro fósil, el debate entre la continuidad y discontinuidad del cambio evolutivo y el no saber quiénes eran los sujetos de la evolución (organismos o poblaciones), debates que se dieron sobre todo a finales del siglo XIX. Para completar la crisis, a principios del siglo XX los biólogos naturalistas de campo y los que aplicaban estudios biométricos (como Pearson y Weldon) que defendían la selección natural y los cambios graduales en la evolución de las especies, se vieron enfrentados a la naciente genética, que planteaba como motor evolutivo los cambios genéticos súbitos y discontinuos, no obstante, como se verá luego, el nacimiento de la genética de poblaciones produjo un acercamiento entre estas dos corrientes del pensamiento evolutivo.

Entre las posiciones que adoptaron la selección natural de una manera dogmática y exagerada, que luego se conocerán como neodarwinismo ortodoxo, encontramos el 
seleccionismo de Weismann (1834-1914) y la posición adaptacionista de Wallace (18231913). Weismann desarrolló su teoría del plasma germinal, que proponía como única responsable de la transmisión de características hereditarias a las sustancias que se encontraban en el núcleo de las células germinales (sexuales). Por tanto las otras células no sexuales, o como se llamarían luego, somáticas, no podrían transmitir características hereditarias. Esta teoría, también conocida como la barrera de Weismann, dejaría desacreditada cualquier tipo de herencia lamarckiana ${ }^{2}$ como también la teoría de la pangénesis propuesta por Darwin, que en alguna medida defendía la herencia de caracteres adquiridos. Por otra parte Weismann, que se asumía a sí mismo como darwinista, pudo reconocer que los cambios transmitidos por las células sexuales, y que según él eran los únicos relevantes, serían afectados por las presiones selectivas, dándole así una preponderancia exagerada a la selección natural como único motor evolutivo. Wallace, por su parte, defendía que todos los caracteres de una especie deberían ser adaptativos y que, por tanto, su origen y su transmisión deben explicarse en términos de selección natural.

En contraste William Bateson (1861-1926), uno de los más importantes divulgadores del trabajo de Mendel y acérrimo defensor de sus postulados, propuso una evolución discontinua (o por saltos) en contraposición a la evolución gradual propuesta por Darwin. Sus estudios, que buscaban encontrar una correlación entre el ambiente y las variaciones de los organismos, fueron infructuosos contradiciendo el neolamarckismo que caracterizó parte del pensamiento de Darwin. En apoyo a estas hipótesis, Hugo de Vries (1848-1935), uno de los redescubridores del trabajo de Mendel, apoyó las hipótesis de Bateson, al proponer el mutacionismo que planteaba cambios bruscos a nivel genético, los cuales serían el motor de la especiación, en detrimento de la idea de que la selección natural fuera la causa del surgimiento de nuevas especies. La no gradualidad de la evolución biológica también fue defendida por el propio primo de Darwin, Francis Galton, quien fundó la biometría en donde se utilizan métodos estadísticos, dando lugar así a la posibilidad de una evolución discontinua.

No obstante, para la década de 1920 las barreras que se habían originado entre los darwinistas naturalistas y los genetistas se fueron debilitando y se empezaron a dar acercamientos conceptuales y metodológicos, que alcanzaron su clímax en la llamada síntesis moderna o teoría sintética. Dichos acercamientos fueron dados, paradójicamente, desde la genética, que como se vio se oponía a la selección natural; pero en este caso fue la genética de poblaciones la que salió al rescate del darwinismo y tuvo como interés de investigación la dinámica de las frecuencias de genes en las poblaciones. Dichos estudios intentaron demostrar que no debía haber conflicto entre la herencia particulada (basada en genes o factores hereditarios mendelianos) y la selección natural.

La base de la genética de poblaciones parte, en principio, de lo que se llamará la ley de Hardy-Weimberg, propuesta en 1908 y que básicamente plantea la constancia de la frecuencia de los alelos en una población en equilibrio, cuando no es afectada por migraciones o mutaciones.

\footnotetext{
${ }^{2}$ Weismann llevó a cabo experimentos con 22 generaciones de ratones, a los que les cortó la cola, y no transmitieron a sus descendientes la ausencia de cola, que sería el carácter adquirido.
} 
Otro concepto destacable en la genética de poblaciones es la eficacia reproductiva. Al respecto, Bowler (1985) plantea que pequeños cambios en la eficacia reproductiva podrían causar cambios drásticos en la frecuencia de genes en pocas generaciones. Esta concepción influirá en trabajos posteriores como el de J.B.S. Haldane (1892-1964), quien con sus trabajos matemáticos relacionados con la frecuencia de genes en una población, defenderá la preponderancia de la selección natural como causa evolutiva, lo que también sería apoyado por el contemporáneo de Haldane, el genetista y estadístico Ronald Fisher (1890-1962). Este último defendió que gran parte de la variación continua se debe a la acción combinada de genes de baja actividad fenotípica y no al ambiente (Sánchez, 2012).

Por otra parte Sewall Wright, aunque compartía la metodología y epistemología de las investigaciones evolutivas basadas en la genética de poblaciones (la cual considera que las poblaciones de organismos se pueden estudiar como poblaciones de genes), al contrario de Fisher sugería que los genes no actuaban como entidades separadas, sino que interactuaban entre ellos originando el fenómeno de epistasis ${ }^{3}$.

En este contexto Wright retoma y modifica el concepto de paisaje adaptativo, introducido por Fisher, para visualizar las relaciones de los genotipos y/o fenotipos con el éxito reproductivo (aptitud o eficacia biológica).

Mientras que para Fisher el paisaje adaptativo solo tenía un pico, en el de Wright se encuentran montañas con diferentes alturas, las más altas muestran picos y entre ellas se encuentran valles. La altura de la montaña representa la aptitud del genotipo, y dependiendo de las condiciones iniciales y la composición genética, la población alcanzará con mayor probabilidad los picos adaptativos más accesibles o cercanos, partiendo de los de menos aptitud, es decir los valles. Es importante aclarar que no hay una tendencia general de la especie o población a alcanzar el pico más alto, ya que existen muchas soluciones locales. En este modelo hay varios mecanismos de evolución, la adaptación por selección natural no es lo único: también están la deriva genética, la extinción y la división en subpoblaciones o demes (Andrade, 2009).

Así pues, en este contexto se dio un amplio consenso entre las dos corrientes de biólogos, naturalistas darwinianos y genetistas, en lo que se conoció como la síntesis evolutiva o teoría sintética de la evolución, o simplemente síntesis moderna, y que consistió en el acuerdo entre diferentes ramas de la biología como la sistemática, paleontología y genética, entre otras, para explicar la evolución biológica desde presupuestos neodarwinistas.

Según Sánchez (2012) las obras más importantes que consolidaron la síntesis moderna, las cuales se analizarán brevemente, fueron:

-Evolution: The Modern Synthesis (1942), de Julian Huxley.

- Genetics and the Origin of Species (1937), de Teodosius Dobzhansky.

-Systematics and the Origin of Species (1942), de Ernst Mayr.

\footnotetext{
${ }^{3}$ Interacción génica no aditiva entre diferentes genes para una característica, es decir, la acción de un gen se ve modificada por la acción de uno o varios genes.
} 


\section{-Tempo and Mode in Evolution (1944), de George Gaylord Simpson.}

La genética evolucionista de Teodosius Dobzhansky (1900-1975) tiene como sustento teórico el estudio de las variaciones, desde el paradigma de la adaptabilidad de las especies a los entornos cambiantes, cuya fuente de variabilidad en la población son los individuos heterocigotos. Dobzhansky explica la aparición de las especies de la siguiente manera: en poblaciones suficientemente pequeñas, la deriva genética empuja a los grupos diferenciados, hacia los diferentes picos adaptativos de su paisaje geográfico y ecológico. Este movimiento es ayudado por mecanismos externos de aislamiento, como las barreras geográficas. El aislamiento genético acabará sellando la variabilidad de unos grupos respecto a otros, dando lugar a la especiación de tipo alopátrico ${ }^{4}$ (Dobzhansky, 1980, citado por Sánchez, 2012).

Por otra parte, Ernst Mayr (1904-2005), ornitólogo, sistemático, biogeógrafo y teórico de la biología, utilizando la metodología propia de los naturalistas, propone el famoso concepto biológico de especie ${ }^{5}$ más allá de su connotación biológica. Mayr consideraba a las especies como entidades reales con distribuciones biogeográficas reales, que son modificadas en gran parte por la selección natural, desde el mecanismo alopátrico principalmente, coincidiendo en este punto con Dobzhansky.

En este contexto George Gaylord Simpson (1902-1984), desde su paleontología evolucionista, intentó resolver un problema que aún sigue sin resolverse completamente y es el de la macroevolución, es decir procesos evolutivos que generarían no solo cambios en las frecuencias génicas de las poblaciones, sino aparición de especies y otros grupos taxonómicos superiores. El problema de la macroevolución, entre otras cosas, se evidencia por lo enormemente fragmentario e incompleto que es el registro fósil, lo que hace muy difícil encajar la idea de una evolución gradual y continua con la evidencia paleontológica. Pero Simpson, concertando apropiadamente una serie de fuerzas evolutivas como la deriva genética, las migraciones, las mutaciones, la recombinación y la selección natural, construyó un modelo de evolución con varios modos y ritmos de cambio, tratando de encajar en él la información del registro fósil y la de los grandes grupos taxonómicos, proponiendo sus famosos tempos evolutivos lento, medio y rápido, que causarían los siguientes procesos evolutivos respectivamente: anagénesis (no especiación), cladogénesis (especiación gradual) y la evolución cuántica o de taxones superiores, logrando así integrar la paleontología a la síntesis moderna, de una manera más o menos aceptable.

Con todo este soporte teórico, la síntesis moderna se consolidó en el congreso de Princeton, en el que especialistas de numerosas ramas de la biología adoptaron un núcleo teórico y metodológico común para continuar sus estudios evolutivos, el cual se puede resumir en los siguientes puntos:

\footnotetext{
${ }^{4}$ Especiación por aislamiento geográfico. Al quedar aisladas dos poblaciones por una barrera geográfica, es posible que queden en condiciones ambientales diferentes y que varíen, en consecuencia, de una manera diferente, a tal punto que después de un tiempo ya no pueda haber entrecruzamiento entre ellas, quedando aisladas reproductivamente $y$, por tanto, dando lugar a dos especies diferentes.

${ }^{5}$ La especie es definida como una población o un conjunto de estas que puede, real o potencialmente, generar descendencia fértil y que está aislada reproductivamente de otros grupos semejantes.
} 
- La evolución biológica es de naturaleza gradual, hasta el punto que muchos fenómenos macroevolutivos podrían explicarse en términos microevolutivos, es decir pequeñas mutaciones en los genes podrían acumularse hasta dar fenómenos de especiación e incluso de aparición de taxones superiores.

- La más preponderante causa de cambio y diversificación biológica es la selección natural, que hace que la mayoría de las características de las especies tengan un valor adaptativo.

-El aspecto poblacional del origen de la diversidad.

- La variación genética surge por azar debido a las mutaciones puntuales o, como hoy en día se conocen, errores en la replicación del ADN; también por recombinación genética durante la meiosis. Ambas variaciones se verán afectadas por el flujo genético, la deriva genética y la selección natural, dando como resultado la evolución, entendida como cambio de frecuencia alélica en una población en el tiempo, es decir entre generaciones.

En este contexto la TSE se utilizó como fundamento teórico-conceptual para explicar muchos fenómenos acaecidos en la historia de los seres vivos, como lo es la aparición de la célula eucariota, pero como se verá en el siguiente apartado, este fenómeno de excepcional importancia en la historia evolutiva de los seres vivos puede ser explicado desde otra óptica que no recurra a los presupuestos de la TSE.

\section{La endosimbiosis seriada}

La edad de la Tierra se ha estimado en unos 4500 millones de años y se cree que las bacterias, organismos procariotas ${ }^{6}$, aparecieron unos 600 millones de años después, luego de que el planeta se enfriara y cesara la lluvia de meteoritos que caía sobre la Tierra. Las bacterias fueron las únicas pobladoras del planeta durante los siguientes 2000 millones de años, es decir un poco más de la mitad de la historia de la vida en la Tierra (Sampedro, 2007). Luego, hace unos 1800 millones de años, aparecieron los primeros eucariotas, según la descripción de la microflora fósil de Gunflit (Canadá) (Tyler, 2003). Teniendo en cuenta estos hechos, uno de los acontecimientos más relevantes en la evolución biológica sería la aparición de los eucariotas, cuyo origen, se pensaba hasta la década de 1960 había sucedido por un proceso gradualista y neodarwiniano, es decir por la acumulación de pequeñas variaciones en las células procariotas.

En este contexto apareció una idea diferente acerca del origen de la célula eucariota, propuesta por Lynn Margulis (1938-2011), que plantea que la aparición de los eucariotas se debió a un proceso de unión simbiogénica ${ }^{7}$ entre tres 0 más bacterias distintas, 0

\footnotetext{
${ }^{6}$ Procariotas entre los que se cuentan las arqueobacterias y bacterias. Se caracterizan por no tener núcleo, ni tampoco organelos como las mitocondrias o los cloroplastos, que sí se encuentran en las células eucariotas que constituyen organismos unicelulares, como protozoos, o multicelulares como hongos, plantas y animales.

${ }^{7}$ La simbiosis se refiere a la relación estrecha entre dos o más organismos de diferentes especies. No obstante, la simbiogénesis supone una adaptación mutua entre los simbiontes, de la cual emergen
} 
cuatro en el caso de las células vegetales. Es decir que el proceso evolutivo de la aparición de las células eucariotas se debió a la unión de las características de diferentes bacterias y no a los cambios graduales, como lo proponían las corrientes neodarwinistas, y su causa última era la simbiogénesis y no la acción de la selección natural, la cual actúa después de formada la nueva entidad biológica, ajustándola y adaptándola al ambiente (Sampedro, 2007).

Margulis llegó a estas conclusiones a finales de la década de 1960, a través del estudio de la estructura de las células. Las mitocondrias, por ejemplo, son cuerpos enroscados que generan la energía necesaria para el metabolismo y Margulis se percató de que se parecían notablemente a las bacterias. Científicos anteriores a ella habían notado esta semejanza ${ }^{8}$, desde el descubrimiento de las mitocondrias en las postrimerías del siglo XIX; algunos científicos como Merezhkovsky en el siglo XIX y Wallin a principios del siglo $X X$ ya habían sugerido que las mitocondrias se originaron a partir de bacterias que vivían en una simbiosis permanente dentro de las células de los animales y las plantas. En las células vegetales había ejemplos análogos. Las células de las plantas y de las algas tienen un segundo conjunto de organelos que utilizan para hecer la fotosíntesis, los cloroplastos, que capturan la energía que reciben de la luz del sol, haciendo posible las reacciones bioquímicas, incluida la combinación de agua y dióxido de carbono para constituir materia orgánica. Los cloroplastos, al igual que las mitocondrias, se parecen notablemente a las bacterias, en especial a las cianobacterias.

Según Sampedro (2007), las evidencias que soportan esta teoría son:

-Muchos genes eucariotas analizados por científicos muestran grandes similitudes con ciertas bacterias ${ }^{9}$.

- Las mitocondrias y cloroplastos transmiten características hereditarias independientemente del núcleo.

- Las mitocondrias de los eucariotas, así como los cloroplastos, contienen fragmentos de ADN cuya organización es semejante a la del ADN de los organismos procariotas.

- Organelos celulares como cloroplastos, bacterias, núcleo e incluso cilios y flagelos, tienen similitudes morfológicas y en su biología molecular con diferentes bacterias.

Según esta teoría, la aparición de la célula eucariota no fue gradual y mediada por la selección natural, es decir por minúsculos y lentos cambios en un organismo procariota que le dieron más adaptación al ambiente hasta formar una célula eucariota, como lo propondría el neodarwinismo ortodoxo. Por el contrario, la fuerza evolutiva que produjo a los eucariotas fue la endosimbiosis, es decir la suma de las funciones y morfología que aportaron bacterias completas y anteriormente existentes, y que hizo emerger una nueva

características heredables por la transferencia horizontal de la totalidad o parte del material genético, lo que conduciría a novedades biológicas evolutivas como el surgimiento de una nueva especie.

${ }^{8}$ Margulis había hecho una revisión exhaustiva de lo propuesto por otros científicos al respecto, entre ellos Merezhkovsky y Wallin.

"A principios del presente milenio, cuando se anunció la secuencia del genoma humano fue una sorpresa que cerca de 250 genes de los más de 30000 genes humanos procedían directamente de bacterias" (Margulis, 2003, pp. 116-117). 
entidad con propiedades que son más que la suma de sus partes (sinérgica) y dio origen a las células eucariotas. No obstante, luego de formarse la primera o primeras eucariotas, seguramente la selección natural jugó un papel en el ajuste de estas a su ambiente.

En cuanto al peso que le da Margulis a las mutaciones en el proceso evolutivo, es mínimo. Según ella, el $99 \%$ de las mutaciones son dañinas, no es factible que el restante $1 \%$ sea significativo. Ella argumenta que el origen de las especies se debe a la simbiogénesis o adquisición de genomas ajenos (Margulis, 2003).

Con el objeto de matizar la propuesta de este ensayo, en el siguiente apartado se mostrarán algunas de las principales diferencias teóricas entre la TES y la TSE.

\section{Paralelo conceptual y epistemológico entre la endosimbiosis seriada y la teoría sintética de la evolución.}

De acuerdo a la revisión hecha en los dos apartados anteriores, las principales diferencias para explicar el origen de la biodiversidad desde las explicaciones planteadas por la endosimbiosis seriada y la teoría sintética se muestran en el Cuadro 1:

\begin{tabular}{|l|l|l|l|}
\hline Aspectos & $\begin{array}{l}\text { Carácter } \\
\text { externo/ } \\
\text { interno }\end{array}$ & $\begin{array}{l}\text { Relaciones } \\
\text { temporales: } \\
\text { gradualismo } \\
\text { /saltacionismo } \\
\text { evolutivas }\end{array}$ & $\begin{array}{l}\text { Importancia de la } \\
\text { selección natural en } \\
\text { el proceso evolutivo }\end{array}$ \\
\hline $\begin{array}{l}\text { Teoría sintética de } \\
\text { la evolución }\end{array}$ & $\begin{array}{l}\text { Externalista: la } \\
\text { selección natural } \\
\text { como la única fuerza } \\
\text { evolutiva externa. }\end{array}$ & $\begin{array}{l}\text { Gradualista: los cambios } \\
\text { evolutivos suceden de } \\
\text { manera gradual y y y selección natural es la } \\
\text { acumulativa. }\end{array}$ & $\begin{array}{l}\text { La } \\
\text { causa más importante del } \\
\text { cambio evolutivo. }\end{array}$ \\
\hline $\begin{array}{l}\text { Endosimbiosis } \\
\text { seriada }\end{array}$ & $\begin{array}{l}\text { Internalista: resalta } \\
\text { las interacciones de } \\
\text { los organismos en } \\
\text { su proceso evolutivo. }\end{array}$ & $\begin{array}{l}\text { Saltacionista: las simbiosis } \\
\text { causan saltos en la aparición } \\
\text { de las especies. }\end{array}$ & $\begin{array}{l}\text { La selección natural es } \\
\text { responsable únicamente del } \\
\text { ajuste fino de los } \\
\text { organismos a su entorno. }\end{array}$ \\
\hline
\end{tabular}

\footnotetext{
${ }^{10}$ La visión internalista proviene de una larga tradición biológica más próxima a disciplinas como la biología del desarrollo, la fisiología y la biología teórica. La evolución, desde este punto de vista, más que como un "mecanismo" generador de orden, se interpreta como un proceso dinámico, orgánico, que emerge de la organización biológica, que puede tener dos puntos de vista: la dinámica interna del organismo desde su composición interna (es el caso de las teorías evolutivas 4 y 5 ) y el internalismo como la dinámica de los organismos con su entorno (teorías evolutivas 3 y 6). En contraste, el externalismo promueve una concepción atomística de las formas de vida en la que las relaciones funcionales internas entre las partes, aunque no ignoradas, son relegadas a un papel secundario. Así, sugiere que toda forma es en principio posible, por lo que en este contexto la teoría de la selección natural proporcionó un "mecanismo" que permitía explicar la sorprendente funcionalidad adaptativa de la vida (teorías evolutivas 1 y 2) (García, 2005).
} 
Cuadro 1. Paralelo epistemológico entre la teoría sintética de la evolución y la endosimbiosis seriada

Respondiendo a la pregunta que titula el presente documento, sobre si la endosimbiosis seriada es una alternativa a la teoría sintética de la evolución, la respuesta es que sí es una alternativa conceptual y epistemológica, debido a que la teoría de la endosimbiosis seriada contrasta y desafía dos de los más importantes presupuestos que ha conferido el marco conceptual de la teoría sintética de la evolución, como son el proceso evolutivo de una manera gradualista y el presupuesto de que el principal motor de cambio es la selección natural, dos concepciones que la teoría propuesta por Margulis no acepta, ya que en lugar de aceptar el gradualismo como un proceso inherente a la evolución biológica, lo niega, preponderando la evolución por saltos, y en cuanto a la selección natural solo la tiene en cuenta como un proceso de ajuste fino de los organismos a su ambiente, luego de que las simbiosis crean los cambios en las especies y, por lo tanto, estas son las que dan cuenta de la biodiversidad y del origen de las especies.

Por otra parte, la opinión general de Margulis sobre el neodarwinismo o teoría sintética de la evolución, y sobre la selección natural, es que esta última no es más que el modo de eliminar los errores genéticos, pero que no puede generar novedad $\mathrm{y}$, por lo tanto, no es la fuerza clave para la aparición de nuevas especies. Propone, en cambio, la simbiogénesis, la unión de organismos, para explicar la evolución. Es decir que la simbiogénesis en general y el fenómeno particular de la endosimbiosis no son hechos aislados en la historia de la vida, sino más bien son fenómenos recurrentes en la evolución y responsables de la biodiversidad, por lo menos en lo que respecta a la opinión de Margulis.

\section{Implicaciones didácticas}

La enseñanza de la evolución biológica ha sido polémica prácticamente desde que se validó la enseñanza de las ciencias en las escuelas. Diversas posiciones culturales desde lo político, filosófico y religioso han puesto límites y objeciones a su enseñanza, por razones de diferente índole (Buskes, 2009, citado por Araújo y Roa, 2011).

Pero si bien se propone enseñar el hecho evolutivo, los mecanismos y dinámica de la evolución que se pretenden enseñar parecen estar dominados, hegemónicamente, por los presupuestos basados en un darwinismo simplificado y la síntesis neodarwiniana, como lo señala Andrade (2009): "Los programas de educación en ciencias se limitan en la mayoría de los casos, cuando tratan el tema de la evolución, a una interpretación superficial del neodarwinismo" (p. 130).

En este contexto, la enseñanza de la evolución desde teorías que no se ajustan a lo planteado por la síntesis neodarwinista, es prácticamente nula en los libros de texto de nivel de educación básica y media, así como en los estándares nacionales que orientan los currículos de las escuelas (Chaves, 2010).

En cuanto a los estándares nacionales para el caso de Colombia, en particular de la biología, propuestos por el Ministerio de Educación Nacional (MEN), llamados La formación en ciencias: jel desafío!, encontramos que se establecen las siguientes 
competencias que el estudiante debe alcanzar con respecto al tema de la evolución y que confirman lo expuesto en este apartado: "Establezco relaciones entre mutación, selección natural y herencia y comparo casos en especies actuales que ilustren diferentes acciones de la selección natural [...] establezco relaciones entre el clima en las diferentes eras geológicas y las adaptaciones de los seres vivos" (MEN, 2008, p. 140).

La causa de este fenómeno podría estar en una visión positivista, reduccionista y hegemónica de la ciencia por parte de ciertos grupos de poder en los grandes centros científicos, así como en la escuela; también a la falta de considerar que un acercamiento a la ciencia se debe dar desde las revisiones histórico-epistemológicas, las cuales hacen posible el surgimiento de nuevas teorías que validan o descartan la nueva evidencia con respecto al estudio de un fenómeno. Al respecto se tiene que:

Si bien la enseñanza de la teoría evolutiva hace parte de los estándares curriculares dados por el Ministerio de Educación Nacional (MEN), los avances que han acaecido en las últimas tres décadas acerca de los mecanismos evolutivos no existen explícitamente como un estándar a enseñar en el área de Biología en las escuelas. Lo anterior podría ser debido a la falta de una continua actualización de los programas de biología, lo cual debería ser imperante, ya que así como avanzan explicaciones de nuevos mecanismos, ritmo y factores de la evolución biológica, así mismo estos avances deberían y deben ser enseñados en la escuela. (Chaves, 2010, p. 176)

Luego de consolidarse el neodarwinismo con la síntesis moderna, se pretendió dar explicaciones a la mayoría de cambios evolutivos en términos de gradualismo, mutación puntual y selección natural. No obstante, estas explicaciones para fenómenos como el origen de la célula eucariota no convencieron a toda la comunidad científica; esto permitió que surgieran explicaciones de estos fenómenos basadas en otras teorías como la endosimbiosis seriada. Sin embargo, estas explicaciones prácticamente no han trascendido a la escuela o no han pasado por el proceso de transposición didáctica para su adecuada enseñanza.

Estos dos fenómenos biológicos son susceptibles de ser enseñados, sobre todo, desde una revisión epistemológica contemporánea del concepto evolución biológica, debido principalmente a que:

- Los problemas que han enfrentado los hombres de ciencia para comprender ciertos fenómenos son, en ocasiones, muy parecidos a los que los estudiantes enfrentan en el momento de aprender ciertos conocimientos. Pero tanto científicos como estudiantes pueden llegar a una aproximación de la explicación de un fenómeno si se reconoce que la ciencia es un conocimiento que está en permanente debate y construcción, y por lo tanto se puede reconocer que una indagación teórica desde lo histórico-epistemológico puede ser valiosa para comprender, enseñar y aprender acerca de un fenómeno.

- Las explicaciones tentativas que se han dado para explicar el origen de la célula eucariota se han forjado resquebrajando, desafiando o complementando lo propuesto por los presupuestos ortodoxos neodarwinistas, desde una indagación de las nuevas 
evidencias empíricas así como desde una revisión epistemológica de teorías anteriores, como fue el caso de la revisión que hizo Margulis de los planteamientos de Wallin en el siglo XX y de Merezhkovsky en el siglo XIX.

\section{Referencias}

Araujo, R. y Roa, R. (2011). Enseñanza de la evolución biológica. Una mirada al estado del conocimiento. Bio-grafía: Escritos sobre la Biología y su Enseñanza, Vol. 4, No. 7, 1535. Universidad Pedagógica Nacional: Bogotá.

Andrade, E. (2009). La ontogenia del pensamiento evolutivo. Hacia una interpretación semiótica de la naturaleza. Bogotá: Universidad Nacional de Colombia.

Bowler, P. (1985). El eclipse del darwinismo. Teorías evolucionistas antidarwinistas en las décadas en torno a 1900. Barcelona: Editorial Labor.

Chaves, G. (2010). ¿Enseñamos Evo-Devo?: Implicaciones de las nuevas hipótesis sobre evolución biológica y su incidencia en la escuela. Bio-grafía. Escritos sobre la Biología y su enseñanza. Vol. 3, No. 4, 176-187. Universidad Pedagógica Nacional: Bogotá.

Crick, F. (1981). Lifeitself. Its origin and nature. London: Simon and Schuster.

Dawkins, R. ( 1988). El relojero ciego. Labor: Barcelona.

Dawkins, R. (2010). Evolución. El espectáculo más grande sobre la tierra. Madrid: Planeta.

Dobzhansky, T. (1937) Genetics and the origin of species. New York: Columbia University Press.

Elgredge, N. (1995). Reinventing Darwin: The great debate at the high table of evolutionary theory. New York: Jhon Wiley \& Sons.

García, T. (2005). Evolución, desarrollo y (auto)organización. Un estudio sobre los principios filosóficos de la evo-devo. Tesis doctoral, Universidad del País Vasco.

Gould, S. (1994). El pulgar del panda. Barcelona: Crítica.

Gould, S. (2010). Ontogenia y Filogenia. La ley fundamental biogenética. Barcelona: Crítica.

Huxley, J. (1942). Evolution: The Modern Synthesis. New York: Columbia University Press.

Margulis, L. y Sagan, D. (2003). Captando Genomas. Una teoría sobre el origen de las especies. Barcelona: Kairos. 
Mayr, E. (1942). Systematics and the Origin of Species. New York: Columbia University Press.

Mayr, E. (1995). Así es la biología. Madrid: Debate.

Mayr, E. (1998). Causa y efecto en biología. En A. Barahona y S. Martínez (Comps.), Historia y explicación en Biología. México: Fondo de Cultura Económica.

Mayr, E. (2006). Por qué es única la biología. Consideraciones sobre la autonomía de una disciplina científica. Buenos Aires: Katz.G

Ministerio de Educación Nacional. (2008). La Formación en ciencias: el desafío. Bogotá: MEN.

Ruse, M. (2008). The philosophy of biology. Cambridge Collections Online. Cambridge: Cambridge University Press.

Sampedro, J. (2007). Deconstruyendo a Darwin. Los enigmas de la evolución a la luz de la nueva genética. Barcelona: Crítica.

Sánchez, A. (2012). Los problemas de la evolución. Madrid: Departamento de Antropología, Lógica y Filosofía de la Ciencia, Facultad de Filosofía. UNED.

Simpson, G. (1944). Tempo and Mode in Evolution. New York: Columbia University Press.

Tyler, S. (2003). Ephitelum- the primary building block for metazoan complexity. Integrative and comparative biology, 43, 55-63. 